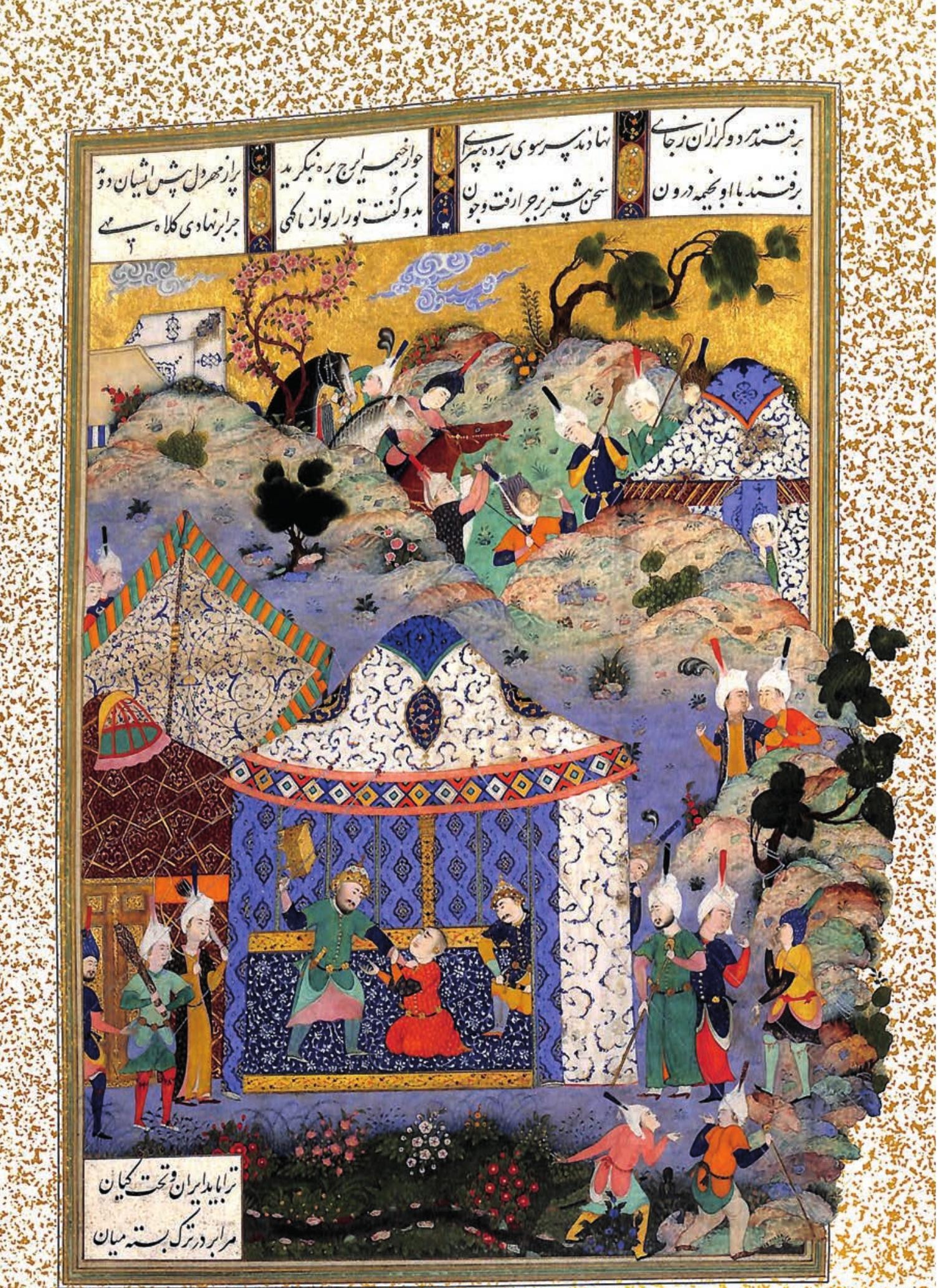




\section{La historia de Zahak y Fereydún}

Pocos elementos hay sobre el escenario, apenas una silla, un bendir, un laúd y dos cornos suizos sugieren sutilmente lo que en el Teatro Santa Catarina está por acontecer. Un poderoso canto en farsi que expresa "[...] pero el que había conocido al Dios omnipresente, se convirtió en un ser soberbio", irrumpe en el silencio y la penumbra de la sala para anunciarnos que el relato está por comenzar. Las primeras líneas se enuncian con fuerza y comprendemos que Yamshid, después de gobernar con esplendor, cede a la soberbia y abre el camino para que Zahak - hombre de actos crueles y oscuros - se erija como nuevo soberano.

Kaveh Parmas - actor de origen iraní-, Indira Pensado y los músicos Manuel Mejía Armijo y Francisco Bringas, aparecen ante nosotros como los narradores de una historia tan antigua como profunda tomada del Shahnamé, también conocido como el Libro de los reyes. No es necesario nada más. La sencillez está puesta al servicio de la imaginación para demostrarnos la fuerza y la actualidad de un relato escrito hace mil años, en el cual nos es reconocible tanto la imagen del poder fundado en la atrocidad como la idea de la esperanza que surge a partir de la rebeldía.

El cuerpo tatuado de los actores parece decirnos todo, ellos están ahí para encarnar a Zahak - hijo de un rey bondadoso, quien tentado por un demonio asesina a su padre y arrebata el poder al soberbio Yamshid-, y Fereydún - héroe predestinado a vencer al cruel soberano y traer consigo la paz-. Personajes que pertenecen a algunos de los relatos que conforman el poema épico más largo escrito por un solo autor y que Indira Pensado y Kaveh Parmas representan alternadamente en cada función. 
Para que esta pieza que lleva por título La historia de Zahak y Fereydún se escenifique ahora en uno de los teatros de la Universidad Nacional Autónoma de México, es necesario realizar antes una traducción. Resulta difícil creer que el gran poema que recupera las historias, relatos, mitos y leyendas persas escrito por Abol Qasem Ferdousí (935-1020), apenas cuente con una sola versión al español realizada en Venezuela por Beatriz de Salas.

Kaveh Parmas no sólo asume la tarea como actor y director de la obra; también realiza una certera traducción del persa al español pensada para la escena, en la que resulta imprescindible la adaptación de algunos pasajes y destaca la capacidad de síntesis para mostrarnos, en poco más de una hora, que incluso los largos regímenes sostenidos en la crueldad y la barbarie tienen fin.

Aun cuando la narración escénica mantiene una correspondencia con la narración oral de la que Ferdousí es heredero, el relato se desarrolla en función de comprender el carácter de los personajes, las acciones y condiciones que permiten el ascenso de Zahak al poder y su caída, el surgimiento del héroe Fereydún y, posteriormente, la venganza de los hijos de Fereydún contra el hermano más pequeño a partir del momento en que se reparten los reinos. Final que, a pesar de tener un desenlace difícil, nos exhorta a mirar con esperanza el futuro a través de la memoria de los actos de aquellos que buscaron dar una luz en medio de la penumbra.

La llegada de Fereydún, el héroe, no es inmediata. Durante mil años Zahak ocupa el trono persa gracias a su unión con el demonio. De tal seducción, dos serpientes negras surgen de sus hombros y son alimentadas con cerebros humanos. Cada día dos jóvenes son asesinados para saciar el hambre de las serpientes y la imagen surge como una posible metáfora acerca de los mecanismos brutales con que se instaura el poder.

Los pasajes por los que estos y otros personajes transitan a lo largo de la historia, las alusiones al transcurso del tiempo - y por tanto al paso de un periodo marcado por las injusticias hacia otro de justa paz-, son ambientados de manera sutil y delicada a través de la iluminación diseñada por Alain Kerriou. La música trasciende la función meramente ilustrativa y acompaña las escenas de tal modo que el laúd y el bendir se convierten en comentadores y narradores de las escenas. 
Los personajes adquieren una gran relevancia no sólo por la manera en que son interpretados por los actores y los músicos a través de un amplio registro vocal y una corporalidad minuciosa derivada de un trabajo de exploración de danza butoh, sino también por el sentido de insubordinación que demuestran a lo largo del relato. Armayel y Garmayel son los primeros en oponerse a los deseos de Zahak. Disfrazados de cocineros, cada día se encargan de alimentar a las serpientes mezclando cerebros de corderos con cerebros humanos para así engañar a Zahak y liberar a uno de los dos hombres destinados a morir. No sin antes aconsejar al sobreviviente huir de la ciudad y esconderse en las montañas. De tal acto subversivo nace el pueblo kurdo y la vida prevalece ante la muerte.

Este y otros momentos tienen la fuerza de remitirnos a nuestro presente aunque se trate de una historia milenaria proveniente de otra latitud. El personaje del herrero - también llamado Kaveh, como el director de la obra-, se acerca a Zahak para enfrentarlo y cuestionarlo por el asesinato de los jóvenes; es entonces cuando reconocemos el valor de enunciar la verdad y de exigir justicia. Aun cuando Zahak le regresa a Kaveh el último de sus dieciocho hijos, el herrero se niega a firmar el decreto donde el tirano se nombra como hombre de verdad y de justicia. Comprendemos entonces la potencia que hay también en nombrar la injusticia y demandar una explicación por ello. En la representación, el diálogo con el presente se establece a través de una acción sugerente: en una pared negra los actores escriben con agua palabras de un alfabeto incomprensible para nosotros. En una imagen que nos remite a los grafitis urbanos, y por tanto a las formas de apropiación del espacio público para demandar justicia, el espíritu de la rebelión de Kaveh, el herrero, queda de manifiesto. Nos es claro, a partir de la historia, que la llegada del héroe es posible porque otros, que se han atrevido a señalar y enfrentar el horror, también lo acompañan. Fereydún sigue los consejos de su madre y deja de mirar el mundo como un niño al comprender que para luchar debe esperar a tener seguidores. La afrenta de Kaveh contra Zahak no es sino la señal de que para Fereydún es el momento de avanzar.

La historia de Zahak y Fereydún sin embargo, no termina con la llegada del héroe y el fin del reinado del déspota. Para Fereydún otras 
batallas acontecen una vez que decide desposar a sus hijos y ponerlos a prueba para repartir los reinos entre ellos. Llegados a este punto, mientras que en el Shahnamé Ferdousí interrumpe el relato para dirigirse a un público de oyentes y compartir en algunas ocasiones parte de sus reflexiones, en esta obra de teatro los actores se dirigen al público para incluirlos dentro del relato e incluirlos como personajes del propio pasaje.

La segunda parte en la que los hermanos dominados por la ira deciden asesinar al hermano más pequeño, a quien Fereydún elige como rey de Persia y maestro de los árabes, demuestra que los periodos de paz tampoco son eternos; la ambición por el poder siempre será una constante. Sin embargo, el último tercio de la obra resulta esperanzador en tanto que hemos visto que los relatos también guardan la memoria de hombres bondadosos que arriesgan su vida por palabras como justicia y esperanza, y por tanto conservan un gran valor.

Manuel Mejía Armijo toca el bendir, nos mira fijamente y por último anuncia: "No suframos / Mañana que nos vayamos de esta vieja morada / Nos reuniremos con los que vivieron hace miles y miles de años". Después de 20 funciones de La historia de Zahak y Fereydún en la Universidad Nacional Autónoma de México, la temporada ha terminado. 